5 Seelig MS, Goldberg P, Kozinn PJ, Berger AR. Fungal endocarditis: patients at risk and their treatment. Postgrad Med J 1979; 55:632-41.

6 Seelig MS, Speth P, Kozinn PJ, Taschgian CL, Toni EF, Goldberg P. Patterns of Candida endocarditis following cardiac surgery: importance of early diagnosis and therapy. Progr Cardiovasc Dis 1974; 17:125-60.

7 Winner HI. A study of Candida albicans agglutins in human sera.J Hyg Camb 1955; 53:509.

8 Murray IG, Buckley HR, Turner CG. Serological evidence of Candida infection after open-heart surgery. J Med Microbiol 1969; 2:463.

9 Evans EGV, Forester RA. Antibodies to Candida after operation on the heart. J Med Microbiol 1976; 9:303-8.

10 Kay JH, Bernstein S, Tsuji HK, Redington JV, ڤึ Milgram M, Brem T. Surgical treatment of Candida endocarditis. JAMA 1962;203:621.

11 Medoff G, Kobayashi GS. Strategies in the treatment of systemic fungal infections. $N$ Engl J Med 1980; $302: 145-55$.

\title{
Correspondence
}

\section{Plasma catecholamines in exercise-induced asthma}

Sir,-The results of Zielinski et al (Thorax 1980; 35: 823) on plasma catecholamines in exercise-induced asthma must be interpreted with extreme caution. Plasma catecholamines were determined by a fluorimetric assay which lacks both specificity and sensitivity and is inadequate for the measurement of plasma catecholamines. The basal values reported for adrenaline are five to ten times higher, and for noradrenaline three to five times higher than those measured by radioenzymatic assay (Barnes et al, Clin Sci 1981; 60:18P), or by high pressure liquid chromatogrophy with electrochemical detection or by gas chromatography-mass spectrometry. The pre-exercise values reported by Zielinski et al correspond to those attained during infusions of $0.075 \mu \mathrm{g} / \mathrm{kg} / \mathrm{min}$ noradrenaline and $0.05 \mu \mathrm{g} / \mathrm{kg} / \mathrm{min}$ adrenaline (FitzGerald et al, Eur $J$ Clin Invest 1980; 10:401) which cause marked cardiovascular and metabolic effects and produce significant bronchodilatation in asthmatic subjects (Barnes et al, $N$ Engl J Med 1980; 303:263).

Using a fluorimetric assay any changes in catecholamines during exercise are very difficult to evaluate. Their demonstration that adrenaline does not rise and that noradrenaline only rises by $50 \%$ during submaximal exercise in normal subjects is in conflict with previous studies where a three to fivefold rise in adrenaline and five to tenfold in noradrenaline have been reported (Galbo et al, J A ppl Physiol 1975; 38:70), and are almost certainly the result of the insensitivity of the fluorimetric assay used. Comparisons between normal and asthmatic subjects are therefore invalid. We have recently measured the catecholamine response to exercise in asthmatic and non-atopic normal subjects using a sensitive radioenzymatic assay. The normal subjects showed a threefold rise in adrenaline and a fivefold rise in noradrenaline whereas the asthmatic subjects showed no rise in adrenaline and cnly a twofold rise in noradrenaline, suggesting an impaired sympathoadrenal response to exercise in asthmatic subjects
(Barnes et al, Clin Sci 1980; 58:4P). The results are discussed in more detail elsewhere in this issue of Thorax.

PETER BARNES
PHILIP IND
MORRIS BROWN
Department of Respiratory Medicine
Hammersmith Hospital,
and Department of Clinical Pharmacology
Postgraduate Medical School
London

Sir, - I fully agree that radioenzymatic assay is more sensitive and specific in measuring plasma catecholamines than the fluorimetric method. Moreover, much less blood is needed. We would have used it if it had been available. Nevertheless I would not agree that the method in question is inadequate for such measurements. Sensitivity of the fluorimetric method is sufficient for plasma measurements if a large sample of plasma is used and measurement procedures are meticulously performed (Jiang et al, Mayo Clin Proc 1976; 51:112). Some authors have reported comparable values of plasma catecholamines using both fluorimetric and radioenzymatic methods (Miura et al, $J$ Lab Clin Med 1977; 89:421, Campese et al, J Lab Clin Med 1980; 95:927). In the papers to which we referred to in our paper, plasma catecholamines were determined using the fluorimetric method. We were not especially interested in basal values which vary depending on the time of the day and can increase in anticipation of muscular exercise (Mason et al, Psych Med 1973; 35:406). We were interested in changes of adrenaline and noradrenaline levels in plasma brought about by physical exercise in three different groups of subjects. For that specific purpose I would find our methods satisfactory.

JAN ZIELIŃSKI Department of Medicine Institute of Tuberculosis Warszawa

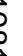

